\title{
La font de Llíria: Edició del primer milacre vicentí publicat (1822)
}

\author{
First edition of La font de Llíria (1822), a milacre of saint Vincent Ferrer
}

\author{
JoAn Vicent Fuertes Zapata \\ juanvifz@hotmail.com \\ Universitat d'Alacant
}

Resum: El present treball estudia el primer milacre vicentí de què es té constància que va ser imprés: $L a$ font de Llíria. Editat anònim a València, el 1822, per primera vegada, és una mostra del teatre popular i de carrer del segle XIX i, a més de ser reeditat en diferents ocasions, arribà a inspirar altres autors posteriors.

Paraules clau: milacres; sant Vicent Ferrer; literatura catalana; litreratura valenciana; teatre; segle XIX

Abstract: The present work studies the first trext printed wich is considered a milacre (dramatic piece about Saint Vincent Ferrer). La font de Lliria was published anonymously in Valencia, in 1822, for the first time, and it is a sample of popular theater of the nineteenth century. It has been reedited on several occasions, and it has come to inspire later autors.

Keywords: milacres, Saint Vincent Ferrer; catalan literature; valencian literature; theater; nineteenth century 


\section{Tradició manuscrita i edicions}

La tradició popular valenciana ha atorgat sovint la capacitat de fer miracles i prodigis a sant Vicent Ferrer, el sant local que més devoció ha tingut en les nostres terres al llarg dels segles, com han demostrat les aportacions d'Escartí (2008; 2013) i Roca (2013) i, encara, la recentíssima de Ferrando (2013). Per una altra banda, de Morella a Agullent, de Casp a Alacant o Barcelona i València, la figura del sant ha perviscut en les anècdotes locals $i$, en aquest sentit, ha despertat tradicions que, de vegades, han passat a la literatura en forma de representacions teatrals senzilles però que, de vegades, han comptat amb la col laboració d'autors de renom. Aquestes manifestacions literàries dialogades han rebut i reben el nom de milacres, atés que el seu desenvolupament es basa en la realització d'un fet miraculós per part de fra Vicent Ferrer. Una de les peces amb més recorregut ha estat la coneguda com el milacre de La font de Lliria, ja que la seua primera notícia data del 1822 i constitueix la primera prova que tenim a hores d'ara de l'arribada a la impremta d'un text d'aquestes característiques. Un text que, com en la resta dels nombrosos casos, allò que destaca als ulls del lector actual és -més enllà del miracle obrat pel frare dominicà- la facilitat amb què el sant podia ser entés, la seua senzillesa, el coneixement dels homes, el gran talent com a predicador $i$ altres valors que han envoltat la figura del sant.

Tot i que els orígens d'aquestes representacions teatrals protagonitzades per infants no estan del tot clars, tot apunta que posseeixen una tradició que es remuntaria al perríode del barroc, atés que va ser a partir del 1638, quan es va celebrar la commemoració del quart centenari de la conquesta de València a mans de Jaume I, quan varen començar a compondre's peces de caire laudatori amb una certa semblança al que després coneixerem com milacres vicentins. Amb tot, aquest tipus de representacions més o menys dialogades ja tenien una tradició medieval anteriror (Sirera 1999). I serà al 1655, amb la festivació del segon centenari la canonització de sant Vicent, quan ja sabrem que en aquelles festes es reciten poemes $i$ algunes representacions d'al legories sobre la figura del dominicà, com ja ha estat indicat de fa temps (Cervera 1983). Dis la festa barroca, aquelles representacions teatrals i escenografies adquirien tot el seu significat (Pedraza 1982).

Ens consta, també, que ja serà al 1817 quan es representa per primera vegada en l'altar del carrer de la Mar -és a dir, sobre un entaulat al carrer que rebrà el nom d'altar- el que es pot considerar com a primer milacre del qual tenim constància, escrit pel pare Lluís Navarro i que porta per títol El fill de l'especier, un text que ens ha pervingut manuscrit i que ha estat reproduit facsimilarment (Cervera 1983). De pocs anys després és el següent text del qual tenim notícia i que, imprés, ha rribat fins a nosaltres: La Font de Llíria, que es va representar també en l'altar del carrer de la Mar de la capital valenciana, el 1822, i que va ser publicat per la impremta de Benet Monfort, el qual pren com a argument el fet suposadament esdevingut a Llíria, el 27 d'agost de 1410 (Martínez Ortiz 1954: 286).

El text, basat en un prodigi realitzat en l'àmbit agrari i relacionat amb la necessitat d'aigua en el camp valencià, assotat tradicionalment per sequeres, degués ser clarament del gust dels qui l'escoltaven i el veien represnetar atentament, $i$ ara com ara tenim constatades una sèrie de reedicions, ja que aquest

SCRIPTA, Revista internacional de literatura i cultura medieval i moderna, núm. 4 / desembre 2014 / pp. 96 - 110 ISSN: 2340-4841 · doi:10.7203/SCRIPTA.4.4488 
milacre va ser reimprès en diverses ocasions, tal com podrem veure a continuació, configurant així una rica tradició textual que encara demana el seu estudi pormenoritzat.

En primer lloc, trobem l'edició que seria realitzada a les pàgines del Diario de la Ciudad de València, el diumenge, 22 d'abril de 1827 (pp. 109-112) i amb el text a dues columnes (Martínez Ortiz 1954: 288).

Una altra edició seria la realitzada per la impremta Gimeno, de València, en 1844, que consta de 13 pàgines, en quart i rústica (Martínez Ortiz 1954: 288).

La quarta edició seria feta, el 1847, per la impremta de Josep d’Orga, i conté 8 pàgines, en holandesa i text a dues columnes. Sobre aquesta edició, en tant que l'última de les d'aquesta tradició anònima, ja vàrem treballar en un estudi anterior i ens remetem a ell (Fuertes 2013; 2014).

Com hem pogut veure, en vint-i-cinc anys, almenys, es va imprimir el text de La font de Llíria en quatre ocasions, i no sabem en quantes més es va representar. A més, tot i ser un text d'autoria anònima, gràcies a l'èxit que tingué en les seues repetides edicions i representacions, tornà a ser font d'inspiració d'autors posteriors que el varen adaptar més o menys, i entre els quals podem destacar els següents textos resultants.

En primer lloc, Josep Campos Marté (s. XIX), va ser un autor de diverses obres còmiques i de milacres, entre els quals es pot destacar el de La font de Llíria, del qual es conserva a l'Arxiu del Col legi Imperial de Xiquets de Sant Vicent Ferrer un exemplar manuscrit, de 45 fulls, a una sola cara (Martínez Ortiz 1954: 277, Sánchez Navarrete 1989; Civera, 2014: 58).

Per una altra part, ens consta també el text de Vicent Hervàs o Chervàs, autor de diversos milacres que se representaren al Col legi de Xiquets Orfes de Sant Vicent Ferrer, i que amb el títol de La Font de Llíria que es conserva en forma de manuscrit de 20 fulls (Martínez Ortiz 1954: 296; Sánchez Navarrete 1989; Civera, 2014: 58-59).

Posteriorment es poden trobar alguns textos impresos que, basats en aquella primera versió del 1822, recreen el fet suposadament esdevingut a Llíria i que, gràcies als treballs de Martínez Ortiz (1955), Sánchez Navarrete (1989) i Civera (2014), podem seguir amb facilitat.

El primer d'aquest grup seria el text elaborat per Francesc Jiménez Marín, notari i cronista de la ciutat de Llíria, que va escriure un Milacre de Sen Visent Ferrer en la vila de Lliria, añ 1410, escrit l'any 1892 com a obsequi al clavari D. Vicent Izquierdo i Alcaide. El text es va editar a València, per la impremta de Josep Canales Romà, en 1892, i consta de 16 pàgines, en quart i rústica. Aquest text es va estrenar el 3 de maig de 1892, a València i es conserva un exemplar a la Biblioteca Municipal de València (Martínez Ortiz 1954: 297).

Una altra versió del milacre vicentí de Llíria seria la realitzada per Joaquim Badia i Adell i que porta per títol La font de Llíria. Milacre per a l'Asosiació de Sant Vicent Ferrer que coloca l'altar en la plasa de la 
Cosntitusió, publicat a València, per Josep Maria Alpuente, el 1907, que consta de 29 pàgines, un exemplar del qual es conserva, també, entre altres llocs, a la Biblioteca Municipal de València.

Finalment, cal esmentar al versió més recent realitzada pel cronista de Benissanó, Josep Cervera i Grifol, titulat L'aigua de Déu, que va ser imprés als tallers de V. Lleonart, per l'Associació de Sant Vicent Ferrer de l'altar del Carme de València, el 1961, i representat en aquell mateix altar l'esmentat any.

Com hem pogut veure, almenys tenim detectades quatre edicions de la versió anònima de La font de Llíria, de la primera meitat del segle XIX, i cinc versions més, de naturalesa molt diversa, que pagaria la pena estudiar, per veure fins a quin punt el relat original va influir sobre els autors posteriors

\section{La versió de La font de Llíria publicada el 1822.}

El text de La font de Llíria en la versió editada a València el 1822 no passa de ser una brevíssima representació amb una acció escènica molt simple. Així, després d'una «Explicasió del Milacre feta per Sen Visent Ferrer, el añ mil cuatresents deu, en la vila de Llíria», trobem el desenvolupament del drama en forma de rahonament entre quatre personatges -Doménec, Antoni, Fontanelles i Tadeo-, on s'explica el miracle obrat per sant Vicent, el qual, abans de realitzar-lo, dirigeix un breu sermó, en prosa, als assistents, per acabar amb un resum de tot allò que s'ha esdevingut, exposat per un dels personatges.

De fet, a La font de Llíria es conté, en primer lloc, un «argument»-o explicació argumental- que pretén situar i posar en context als lectors:

En 26 de agost, l'any 1410, ixqué sant Vicent de València en desix de visitar alguns pobles del reine. Arribà a la vila de Llíria cuan sos vehins estaben molt afligits per haber-se'ls secat la caudalosa font que els proporciona aigua per a beure y regar el terme. Representaren el seu desconsuelo al sant, qui, compadeixcut del contratemps que patien, celebrà, segons sa costum, misa, y pasà al punt a hon estaba el manantial, que entonces era un sech arenisch; però, a penes el sant donà la bendició, de repent tornà a manar com ans un gran colp de aigua, y així ha perserverat y persevera en el dia (Milacre 1822: 2)

Aquesta explicació, que té una clara voluntat de fer-nos entendre que la notícia del fet no és cap cosa inventada, sinó que es troba ben datada en la tradició, a més, aprofita de revisió del conjunt de l'obra, ja que compila, en poques línies, el que tot seguit es desenvoluparà. I això, fins al punt que el text ara reproduït deriva directament -en traducció al català- de l'obra que llavors corria com la més reputada pel que respecta a la biografia del sant valencià. Ens referim a la Historia de la portentosa vida y milagros de san Vicente Ferrer, de Francesc Vidal i Micó, que havia conegut i coneixeria encara diferents edicions. De l'estampació de 1735 reproduïm el fragment que ara ens interessa:

En día veinte y seis de agosto salió de Valencia, con deseo de visitar algunos lugares del reyno.

Llegó a la villa de Liria, cuyos vecinos estavan afligidos por avérseles secado su caudalosa fuente, 


\begin{abstract}
que era su alivio y riqueza, pues de ella pendían en gran parte sus cosechas. Representaron su desconsuelo al santo, quien, compadecido del contratiempo que padecían, celebró, según su costumbre, missa, y luego, con los religiosos fue al puesto que antes era el manantial de la fuente y entonces un arenisco sequeral. Pero luego que el santo le dio su bendición, de repente bolvió a manar, como antes, un crecido golpe de agua. Y así ha perseverado perenemente hasta oy. Para su consistencia les dexó el santo una oración que compuso al intento y se dice cada día en la missa conventual. Por el tiempo se labró junto a la fuente una hermita, dedicada al mismo santo, que hoy poseen los religiosos trinitarios (Vidal i Micó 1735: 154).
\end{abstract}

Com hem pogut comprovar, la traducció és quasi literal i, per tant, es pot considerar l'obra de Vidal i Micó la font primera des d'on s'inspiraria l'anònim autor del milacre, el qual va haver de desenvolupar tot allò que no apareixia a l'obra del XVIII. I així, tot seguit trobem la conversació entre dos camperols, que forma la major part del text i s'estructura en un parell d'escenes de desigual duració i amb to jocós. Finalment trobem la incorporació de sant Vicent a l'escenari, que reacciona després de les peticions d'auxili efectuades pels altres dos personatges i entre les quals destaquen algunes que, aparentment, són fetes en nom de tot el poble. Així, Antoni suplica: «Pare Vicent, per Jesús/ y la sang derramà,/ que li suplique al Senyor/ a Llíria mire en pietat/ y aigua altra volta nos done!». Al mateix temps, Fontanelles afegeix: «És tanta la sequetat,/ pare Vicent, que patim,/ que si Déu per sa bondad/ no nos torna a donar aigua,/ tota Llíria mor de fam».

Sant Vicent, commogut, intervé amb un breu sermó en prosa:

Pues llirianos, tota volta que vosatros coneixeu la necessitat que tenim de aigua, y que sols podeu recibir-la de la qui tot ho pot; ¿com no procureu viure de manera que dobleu al Senyor per a que os favorixca? Els pecats són la causa de totes les calamitats que patiu. Y totes les plagues, pestes, guerres, terremotos, inundacions, sequetats y atres azots en què el Senyor aflix als hòmens, són efectes de la culpa. Sí: no ho dubteu! El pecat és el que arma el braz de Déu y la penitència el que el desarma. Penitència, pues, y mudança de vida, que si així de tot cor ho prometeu, yo confie en Jesucrist que tindreu atra volta aigua. Em doneu paraula de viure com a verdaders cristians?

Tots responen afirmativament i el sant conclou dient: «Pues baix de este coneixement, y avivant la vostra fe, yo faré la bendició en nom del Pare y del Fill y de l'Espirit Sant. Y a la Santísima Trinitat li deureu este benefici, y no a mi que soch gran pecador». Així doncs, la resta de personatges aclamen sant Vicent i li donen les gràcies a Déu, i aquesta acció de gràcies col lectiva clou l'obra.

Això seria, comptat i debatut, el que es conté a l'edició del milacre del 1822. A l'imprés del 1847, però, es contenen una sèrie de textos laudatoris que solen aparéixer amb freqüència en aquestes publicacions. Són versos que es trobaven destinats a decorar l'escenari on es representava l'acció teatralitzada i, en aquest cas, cal destacar un psalm de clara exaltació local. A més, s'acompanya el text amb un sonet i una dècima en valencià i dues octaves i una altra dècima en espanyol, de clar to encomiàstic, cap al sant. Sense oblidar que l'última dècima, curiosament, fa una clara defensa de la llengua nacional. Aquests versos són com segueixen:

SCRIPTA, Revista internacional de literatura i cultura medieval i moderna, núm. 4 / desembre 2014 / pp. 96 - 110 ISSN: 2340-4841 · doi:10.7203/SCRIPTA.4.4488 
Soneto

Predicant el juí tan olvidat y el cel que per tan pocs és apetit y el infern que a ser més aborrit nos lliurara de caure en el pecat, y el càrrech rigurós y comprobat $\mathrm{y}$ al vista de un jutge tan sentit, y lo eficaz del fallo, que complit serà a l'instant que siga pronunciat, conseguí sant Vicent que els seus paisans y tot bon espanyol y el estranger es conduhiren com a bons cristians. $\mathrm{Y}$ estos bons pares, al donar-nos ser, també nos daren uns consells tant sants y per modelo a Vicent Ferrer.

Siempre Vicente a su patrio suelo Muestras le dio de amor y santidad, prodigando do quiera gran consuelo, remediando cualquier necesidad: hable Liria, si no; diga su celo por darle agua en la sequedad. Y allí bien hizo, en donde hizo estància: más sobre el suelo que le vio en la infància.

\section{Dècimes}

Temau y doneu-li honor

a Déu-Vicent predicava-,

y en eixe asunt desplegaba

les veles del seu fervor:

ell de Déu ple de temor,

als vicis contrarestà

fort; per lo temor obrà.

$\mathrm{Y}$ hui clar en ell se veu,

que el home que tem a Déu, eixe nunca por tindrà.

(Milacre, 1847: 6)
Octaves

Un altar magestuoso se levanta de Vicente en obsequio peregrino, y alegre el eco de la fama canta sus virtudes y espíritu divino: se goza el pueblo, y con placer se encanta; pero suele entre tanto algun mezquino ladrón ratero, a tales encantados, dejarles los bolsillos aliviados. 
El milacre efectuat per sant Vicent es troba immers en una societat agrària $\mathrm{i}$ amb una crisi de subsistència alimentària, per la qual cosa es pot veure que clarament té un clar aspecte material. Ara bé, també es pot detectar un clar missatge sobre la fe: sense Jesucrist, la societat medieval no podia viure, ni tampoc aquella societat del segle XIX que pretenien crear distintes classes socials. A més, la religió del segle XIX també tenia un paper molt destacat, barrejat amb les opcions polítiques. I no és d'estranyar que els personatges i l'estructura en els milacres es vegen afectades per fragments d'altres gèneres als quasl estaven acostumat el poble, com ara els sermons, la funció política dels quals era evident (Casanova \& Martínez 2001). Aquest fet, encara, es pot observar de forma clara si s'estudia com el text del milacre recorda altres gèneres, com ara el de la literatura de canya i cordell (col loquis, solil loquis, raonaments, etc.) que tenien una fortíssima tradició des del XVIII i que, pels mateixos anys de la primera edició del milacre de La font de Llíria mostrava una gran vitalitat en figures com la de Branchat (Escartí \& Roca 2010); o els sermons ja esmentats. I això, fins al punt que el milacre de La Font de Llíria ofereix el diàleg dramatitzat dels personatges en vers -tal com era d'habitud en els col loquis-, mentre que el sermó del sant ens apareix escrit en prosa, tal com eren pronunciades les homilies des de la trona.

En conjunt l'obra ofereix una caracterització elemental dels personatges i presenta una estructura teatral prou dèbil. Tanmateix, no hem d'oblidar que el text presenta una escassa voluntat de complexitat dramàtica, ja que pretén bàsicament fomentar la devoció al sant i enaltir la seua figura, uns aspectes que es troben a l'eix central de l'obra. Les escenes del milacre de La Font de Llíria són vives, senzilles, dinàmiques, plenes de gràcia $i$, fins i tot, amb una certa malícia elemental que, tanmateix, poc o gens no s'ajustarien a una situació de desesperació i crisi de subsistència, tal com vol el context del miracle efectuat pel sant. I, encara, amb anacronismes evidents.

Finalment, cal destacar com aquests milacres i les seues corresponents representacions han contribuit a mantenir una certa dignificació de la llengua dels valencians de finals del segle XVIII i de principis del segle XIX. De fet, no solament pel record que poguera despertar el gènere, sinó per la devoció que va fomentar al sant. El text, tant per la seua antiguitat com pel seu caràcter, cal situar-lo entre els que ajudaren clarament a definir i consolidar el gènere $i$, òbviament, no sols va influir en les diferents reedicions -amb modificacions més o menys evidents-, sinó que, com hem vist, va ser motiu d'inspiració en autors molt posterirors. 


\section{Bibliografia}

Casanova, Emili \& Martínez, Francesc (2001) «La guerra i la paraula. Sobre els sermons patriòtics en valencià durant la Guerra de la Independència», Caplletra, 31, pp. 213-240.

Cervera, Juan (1983) Los milacres vicentinos en las calles de Valencia, València, Del Cenia al Segura.

Civera Marquino, Amadeo (2014) «Manuscrits i edicions impreses relatives al Milacre de la font de Llíria», Festes en honor a Sant Vicent Ferrer, Llíria, Confraria de sant Vicent Fererr, pp. 57-60.

Escartí, Vicent Josep (2008) «A propòsit de l'ús del valencià en els centenaris de la canonització de sant Vicent Ferrer (1555, 1655 i 1755)», En el món de sant Vicent Ferrer. València, Denes, pp. 51-70.

Escartí, Vicent Josep (2013) «El record de sant Vicent Ferrer durant l'edat moderna (ss. XVXVIII)", dins Els valencians en el Compromis de Casp i en el Cisma d'Occident, València, Institució Alfons el Magnànim, pp. 459-502.

Escartí, Vicent Josep / Roca Ricart, Rafel (2010) «El clérigo valenciano Vicent Manuel Branchat contra Napoleón. Ideología, literatura y lengua», Cahiers de civilisation espagnole contemporaine, 6, http://ccec.revues.org/index3180.html

Ferrando, Antoni (1987) «La literatura popularista al País Valencià durant la Decadència», Estudis de literatura catalana al País Valencià. Benidorm/Alicante, Ajuntament de Benidorm / Universitat d'Alacant, pp. 55-74.

Ferrando, Antoni (2013): Sant Vicent Ferrer en la historiografia, la literatura, l'hagiografia i l'espiritualitat al segle XV, València, Institució Alfons el Magnànim.

Fuertes Zapata, Joan Vicent (2013) «Teatro popular valenciano: El milacre de Llíria», dins Escribir y persistir. Estudios sobre la literatura en catalán de la Edad Media a la Renaixença, vol. III, Buenos Aires / Los Angeles, Argus-a, pp. 48-66.

Fuertes Zapata, Joan Vicent (2013) «A propósito del milacre de la Font de Llíria», Festes en honor a Sant Vicent Ferrer, Llíria, Confraria de sant Vicent Fererr, pp. 81-83.

Martínez Ortiz, Josep (1954) «Ensayo de un catálogo de milacres de San Vicente Ferrer», Revista Valenciana de Filología, IV, pp. 239-264.

Milacre que obrà el pare sant Vicent Ferrer, titulat «La font de Llíria» y es representa este any en el carrer de la Mar. València, Josep d'Orga, 1847.

Pedraza, Pilar (1982) Barróco efímero en Valencia. València, Ajuntament de València.

Roca Ricart, Rafael (2013) «El record de sant Vicent Ferrer al llarg dels segles XIX i XX», dins Els valencians en el Compromís de Caspi en el Cisma d'Occident, València, Institució Alfons el Magnànim, pp. 503-526.

Sánchez Navarrete, Manuel (1989) «La Font de Llíria en els milacres de sant Vicent Ferrer», Fira $i$ festes de Sant Miquel, Llíria, Ajuntament, pp. 59-61. 
Joan Vicent Fuertes Zapata. La font de Llíria: Edició del primer milacre vicentí publicat (1822)

Sirera, Josep Lluís (1999) «Els miracles de sant Vicent», dins A. Ariño (ed.) Teatre en la festa valenciana, Valencia, Consell Valencià de Cultura, pp. 241-258.

Vidal y Micó, Francesc (1735) Historia de la portentosa vida y milagros del valenciano apóstol de Europa, san Vicente Ferrer, València, Josep Esteban Dolz.

SCRIPTA, Revista internacional de literatura i cultura medieval i moderna, núm. 4 / desembre 2014 / pp. 96 - 110 ISSN: 2340-4841 · doi:10.7203/SCRIPTA.4.4488 


\title{
4. Apèndix. Edició del text.
}

\author{
[LA FONT DE LLÍRIA]
}

[f. 1 r.]

\author{
EXPLICASIÓ
}

DEL MILACRE FET PER SEN VISENT FERRER, EL AÑ MIL CUATRE-SENTS DEU, EN LA VILA DE LLÍRIA, EL CUAL SE REPRESENTA ENGUAÑ, AL VIU, EN EL ALTAR PRINSIPAL DEL CARRER DE LA MAR DE ESTA SIUTAT DE VALÈNSIA.

El dia vint-i-sis de agost de l'añ mil cuatre-sents deu ixqué de València sen Visent, en desich de visitar alguns pobles del reyne. Aplegà a la vila de Llíria, cuyos veïns estaben aflichits per haberse'ls secat la sehua font caudalosa, que era son alívio y riquea, pues de ella pendien en gran part les sehues cullites. Representaren el seu desconsuelo al sant, qui, ple de compasió del contratemps que patien, selebrà, segons costum, misa, y luego que concluí, en los relichosos anà al puesto que abans era el manantial de la font y entonces un arener sequeral. Però, luego que el sant féu la bendisió, de repent tornà a manar, com abans, un gran colp de aygua. $\mathrm{Y}$ així ha perseverat perenement hasta hui. Per a la sehua consistènsia els deixà el sant una orasió que compongué a l'intent, y se diu cada dia en la misa conventual. Per lo temps se labrà, chunt a la font, una ermita dedicada al mateix sant, que hui poseïxen els relichiosos trinitaris.

\section{RAONAMENT}

Doménec: Cada volta que a este siti

me du la casualitat,

de amargura el cor me s'ompli

sens poder-ho remediar.

Antoni: Lo mateix em pasa a mi

y puc dir-te, en veritat, que nunca volguera vindre

per a no entristir-me tant.

[f. 1 v.] Fontanelles: Cualsevol que ha vist la font

tan hermosa y abundant

$y$ ara àrida y seca,

de pena es mor y pesar.

Tadeo: Vosatros teniu un cheni

molt pensatiu y agobiat. 
Yo sempre que vinc así vinc a riure'm y a ballar. ¿Quines paelles tan bones, en este siti yo fas! Y may l'aigua falta em fa, pues la gaste de les fonts aquelles del Pla de Cuart. ¡Eixes si que sentiria que se secaren, caram! QQué turmiento para un hombre que sol churripamplear!

Doménec: Amic Tadeo, no estem ara en tems de truanechar. Segons la ocasió, així es parla. En tems de plorar: plorar.

Tadeo: ¿Yo he de plorar sense ganes?

¡No estaria mal el ball!

Doménec: A tu ningú et diu que plores, però sí deus procurar el no gastar bufonades en tems de tants de treballs.

Tadeo: Pues hòmens, mudeu-me el cheni. Fontanelles: Tu és qui te'l deus mudar, o remediar-lo o contindre'l, que en la teua mà això està. Tadeo: La carabina d'Ambrosi, ¿qui un cheni pot remediar? Lo que en los volquers es pren, en la mortalla...

Antoni: ¡Incapàs!

No parles tantes asnades, perquè cuant més parlaràs, més demostraràs qui eres, ¿Tu casi voldràs probar que, el que té un visi o mal cheni, en ell presis morirà?

¿Y la gràsia del Señor? ¿Y aquella presiosa Sanc, que derramà per nosatros 
als més pèsims no fa sants?

¿La Magdalena, Cortona, Tais, Agustí y sen Pau, no foren tots pecadors $\mathrm{y}$ ara en lo alt tots estan? Però, ¿̇per què, amic Tadeo? ¿Per què varen cooperar als impulsos de la gràsia? [f. 2 r] Tadeo: ¡Reparen en quin fangar que nos ha ficat Antoni! Un sermó nos ha encaixat, així com un teatino.

A poc rato em fa plorar.

Fontanelles: Amic Tadeo, a la nostra.

Tadeo: ¿Qui la paella ha portat?

Fontanelles: No venim así a fartades.

Tadeo: Pues em porteu engañat, Però no del tot, que porte un trescolaví tal cual.

Doménec: Vamos, baste ya de chanses, parlem en formalitat. La vinguda es reduïx, a veure com alcanzar de Déu que atra volta nos done aygua en la font.

Tadeo: ¡Bueno va! Yo també me alegraria de què es pogueren regar totes estes ortes que ara seques y àrides estan.

Fontanelles: Pues llàgrimes pronte tots, per veure com ablanar al Señor que està en nosatros segurament ennuchat. Plorem, llirianos, plorem nostres culpes y pecats.

Tadeo: Ells han pegat en què plore y auré a l'últim de plorar. ¿Com hu é de fer sense ganes? 
Yo faré com altres fan, que el dia que es mor la dona

tot es arrapar-se el cap y pegar uns grans suspirs y una llàgrima no els cau.

Doménec: Llirianos, pense una cosa:

a nostra vila ha arribat, eixe gran predicador, eixe dominico gran, el mestre Visent Ferrer, que alcansa del Señor tant, y dihuen que fa milacres a porrillo y a grapats.

Anem, pues, y supliquem-li que se'n vinga así un instant, que, com ell vullga, tindrem font atra volta abundant. [f. 2 v.] Tadeo: Pues aneu, Antoni y tu, que els dos sou tan ben parlats, y supliqueu-li que vinga, $\mathrm{y}$ aforreu-me de plorar. Antoni: ¿Anem-se'n, Mariano?

Doménec: Anem-se'n.

Espereu-se, que en lo sant anem a vindre al momento.

Tadeo: Déu fasa que ixcam del pas

y que fasa así un milacre este home tan afamat, perquè si no estos malignes per forsa em faran plorar.

Fontanelles: ¡Em consumixes de ohuir-te!

¡Tota la sanc tinc a cualls!

¡Tot ho parles per un terme!

Tadeo: ¡Fontanelles, estàs formal!

Fontanelles: Ya se ve que em formalise; no em pareix chens regular que en asuntes d'esta clase gastes bufonades tals. 
Mariano y Antoni venen en compañía del sant.

Amic Tadeo, et suplique mires dabant de qui estàs. Tadeo: Un novisi capuchino, Fontanelles, en mi voràs. Doménec: Esta és la font, pare mestre, que de poc tems a esta part no mana una gota de aygua y era abans tan abundant que es regaba tot asò y era fèrtil sense igual. Y ara està com vosté veu, tot el terreno herial.

Antoni: Pare Visent, per Chesús

y la sanc que derramà, que li suplique al Señor a Llíria mire en pietat y aygua atra volta nos done. Fontanelles: És tanta la sequetat, pare Visent, que patim, que si Déu per sa bondat no nos torna a donar aygua, tota Llíria mor de fam.

[f 3 r.] Sen Visent: Pues, llirianos, tota volta que vosatros coneixeu la necesitat que teniu de aygua y que sols podeu resibir-la de la mà de qui tot ho pot, ¿com no procureu viure de manera que dobleu al Señor per a què vos favorixca? Els pecats són la causa de totes les calamitats que patim. Y totes les plagues, pestes, terremots, inundacions, sequetats y atres asots en què el Señor aflix als hòmens, són efectes de la culpa. Sí; no ho ducteu: el pecat és el que arma el bras de Déu y la penitènsia el que el desarma. Penitènsia, pues, y mudanza de vida, que si així de tot cor ho prometeu, yo confie en el nom del Señor que tindreu altra volta aygua. ¿Em doneu paraula de mudar de viure?

(Tots responen a una veu: Sí, pare!).

Pues baix d'este coneixement, y avivant la vostra fe, yo faré la bendisió, en nom del Pare, del Fill y de l'Espirit Sant, y a la Santísima Trinitat li deureu este benefisi, y no a mi, que sóc la criatura més infelís que milita sobre la terra.

(Fa una bendisió, y mana la Font).

Tots: ¡Viva el pare sen Visent Ferrer!

Tadeo: Ningú ducte d'este fet; 
Joan Vicent Fuertes Zapata. La font de Llíria: Edició del primer milacre vicentí publicat (1822)

la font ben patent està

i els de Llíria tots confesen

ser un milacre del sant.

En el añ mil cuatre-sents deu,

aflichits per sequetat,

al sant varen acudir

tots contrits y humillats.

Apenes acabà la misa,

el apòstol valensià,

formant poderosa creu,

invocant la Trinitat,

la font manà molt copiosa

y hasta el dia no ha parat.

Con que, així, valensianets,

si al sant au d'agradar

demaneu-li molt contrits,

detestant tots los pecats.

VALÈNSIA

PER DON BENITO MONFORT, AÑ 1822.

SCRIPTA, Revista internacional de literatura i cultura medieval i moderna, núm. 4 / desembre 2014 / pp. 96 - 110 